DOI: $10.3727 / 096368913 \times 667709$

CT-1016 Accepted 04/24/2013 for publication in "Cell Transplantation"

\title{
Paracrine mechanisms of Mesenchymal Stem cell-based therapy: Current status and perspectives
}

\author{
Xiaoting Liang, M.Sc ${ }^{1}$; Yue Ding, M.Sc ${ }^{1,2}$; Yuelin Zhang, MD ${ }^{1}$; Hung-Fat Tse, MD, \\ PhD. ${ }^{1,3^{*}}$; Qizhou Lian, MD, $\mathrm{PhD}^{1,3,4 *}$
}

${ }^{1}$ Cardiology Division, Department of Medicine, University of Hong Kong, Hong Kong; ${ }^{2}$ Organ Transplantation Institute, Xiamen University, Fujian Province, PR China; ${ }^{3}$ Research Centre of Heart, Brain, Hormone, and Healthy Aging, Li KaShing Faculty of Medicine, University of Hong Kong, Hong Kong; ${ }^{4}$ Department of Ophthalmology, Li KaShing Faculty of Medicine, University of Hong Kong, Hong Kong

*Correspondence:

Qizhou Lian, MD, PhD.

Cardiology Division,

Department of Medicine,

The University of Hong Kong,

Hong Kong.

Tel: $+852-21899752$

Fax: $+852-28162095$

Email:qzlian@hku.hku.hk (Q Lian) or hftse@hku.hk ( HF Tse)

Running Header: Paracrine mechanisms of Mesenchymal Stem Cells 


\begin{abstract}
Mesenchymal stem cells (MSCs) are one of a few stem cell types to be applied in clinical practice as therapeutic agents for immunomodulation and ischemic tissue repair. In addition to their multipotent differentiation potential, a strong paracrine capacity has been proposed as the principal mechanism that contributes to tissue repair. Apart from cytokine/chemokine secretion, MSCs also display a strong capacity for mitochondrial transfer and microvesicle (exosomes) secretion in response to injury with subsequent promotion of tissue regeneration. These unique properties of MSCs make them an invaluable cell type to repair damaged tissues/organs. Although MSCs offer great promise in the treatment of degenerative diseases and inflammatory disorders, there are still many challenges to overcome prior to their widespread clinical application. Particularly, their in-depth paracrine mechanisms remain a matter for debate and exploration. This review will highlight the discovery of the paracrine mechanism of MSCs, regulation of the paracrine biology of MSCs, important paracrine factors of MSCs in modulation of tissue repair, exosome and mitochondrial transfer for tissue repair and the future perspective for MSCbased therapy.
\end{abstract}

Key words: Mesenchymal stem cells, mechanism, paracrine effects

\title{
Introduction
}

The initiative of stem cell research can be traced back to 1963 when James and Ernest first identified stem cells in mouse bone marrow (12). A subsequent growing body of evidence that confirms the existence and function of stem cells now makes them the optimal source for tissue engineering and regenerative medicine. According to statistical data registered on Clinical 
Trials.gov to date, stem cell-based therapeutic approaches now total 4230 globally: the transition from laboratory bench to bedside has begun. Based on the technical feasibility, promising curative effects, reduced economic cost and circumvention of ethical issues, mesenchymal stem cells (MSCs), that account for up to 300 cases of the 4230 (7.0\%, 300/4230), have become the most common and effective cell source in cell-based treatment. The fascinating therapeutic effects of MSCs in various life threatening human diseases, including cerebral spinal cord injury, hematological disorders, cardiovascular diseases, diabetes, immune diseases, GvHD (graft versus host diseases), and cancer are well documented. Nonetheless the in-depth mechanisms of how MSCs act remain a matter for debate and exploration. The generally putative concepts cover trans-differentiation, cell fusion, paracrine effects, microvesicles carrying mRNA or miRNA and mitochondrial transfer (figure 1) $(8,9,16,30,33,34,42,96,100,134)$. This review will focus on the paracrine effects of MSCs, the most comprehensive and enduring mode of action that ascribes to functional recovery in both acute and chronic responses.

\section{Discovery of paracrine mechanism of MSCs}

The secretion of cytoprotective factors by MSCs was first reported by Gnecchi and colleagues $(33,34,56)$. The novel observation that modified MSCs overexpressing Akt (Akt-MSCs) could prevent ventricular remodeling and reestablish heart function in less than 72 hours following surgical myocardial infarction (MI) and cell transplantation raised the possibility of an action other than a myogenic pathway that would not be evident in such an extremely brief time period. Previous studies also pointed out that the limited frequency of the transplanted stem cell-derived cardiomyocytes (CMCs) was unlikely to be the main contributor to the marvelous amelioration of the ischemic organs $(5,47,58,81)$. Thus a new mechanism was proposed in which the injected MSCs might release trophic factors that contribute to myocardial protection following an ischemic insult. This hypothesis was then confirmed by evident improvement in cardiac performance following injection of conditioned medium (CM) collected from hypoxic Akt-MSCs (Akt-MSCs-CM) into an induced $\mathrm{MI}$ model. In vitro experiments also demonstrated that the hypoxic Akt-MSCsCM could protect ventricular CMCs against apoptosis when subjected to a 
hypoxic challenge. Other valuable factors were also identified, including VEGF (vascular endothelial growth factor), bFGF (basic fibroblast growth factor), HGF (hepatocyte growth factor), and TB4 (thymosin beta 4), that were upregulated in the Akt-MSCs compared with the vector-MSCs. The paracrine effects of MSCs not only emerged as an original mechanism of action, but also inspired the future biological and clinical application of purified cytokines in ischemic injury. Kinnaird et al. reported that growth of endothelial cells (EC) and smooth muscle cells (SMC) could be stimulated by the conditioned medium of MSCs (MSCs-CM) in a dose dependent manner. This phenomenon could be partly explained by the high level of VEGF and bFGF detected in the MSCs-CM. Nonetheless neutralization using anti-VEGF and anti-bFGF antibodies could only partly impair this effect, suggesting other potential beneficial chemokines or cytokines needed to be determined (54). Subsequent studies located more salutary factors essential for remission of injury that could be classified into 5 categories as follows:

\subsection{Immunomodulation factors}

Bartholomew et al. first observed the immunomodulatory function of MSCs as evidenced by their dose-dependent inhibitory effect on the cell proliferative response of allogeneic mitogen-stimulated lymphocytes in mixed lymphocyte culture (MLC) (11). The skin transplantation model also verified prolonged skin graft survival following intravenous administration of MSCs compared with a saline injection group. Contrary to this, Di Nicola's data demonstrated that this immunosuppressive feature was in part due to soluble factors as shown by the continued suppressive effect on the proliferation of T-lymphocytes in a transwell system, and excluded the possibility of cell-cell communication (20). The proliferation of T-cells could be sectionally restored with the addition of monoclonal antibody TGF- $\beta 1$ (transforming growth factor- $\beta 1$ ) or HGF, suggesting both cytokines were involved in the process. Inducible IDO (indoleamine 2,3-dioxygenase), an enzyme that catalyzes conversion from tryptophan to kynurenine and subdues the T-cell response to autoantigens and fetal alloantigens, was detected in MSCs simulated by IFN- $\gamma$ (interferon $\gamma$ ) (76). With respect to IFN- $\gamma$ primed MSCs, another article proposed that IFN- $\gamma$ played a crucial rule in the MSC-T lymphocyte interplay by up-regulating the expression of $\mathrm{B} 7-\mathrm{H} 1$ on MSCs, a known co-inhibitor molecule of the immune response (108). Selmani et al. discovered that HLA-G5 (human leukocyte 
antigen class I molecule 5) secreted by MSCs, possessing the ability to contact with allo-stimulated $\mathrm{T}$ cells, was responsible for the immunosuppressive functions of MSCs on T-lymphocyte and NK (natural killer) cells, as well as the expansion of the inducible $\mathrm{CD} 4^{+} \mathrm{CD} 25$ highFOXP3 $^{+}$regulatory T cells (106). Apart from the influence on lymphocytes, the bioactive components of MSCs were shown to facilitate the transition of macrophages from the pro-inflammation phenotype M1 (classical activated macrophage) to the anti-inflammation phenotype M2 (alternative activated macrophage). This was proposed as one of the mechanisms that occurs in the early stage of tissue deterioration $(2,17)$. As there are three major stages of the immune response- 1 . antigen recognition and presentation; 2 . $T$ cell activation, proliferation and differentiation; 3. effective stage. The immunosuppressive privilege of MSCs not only exists during the 2 nd stage on T cells, but also modulates the very first step by interaction with antigen-presenting cells(APCs). Jiang et al. presented evidence that MSCs inhibited the differentiation, maturation, and function of dendritic cells (DCs) derived from $\mathrm{CD} 14^{+}$monocytes (45). The mature DCs that underwent MSCs co-culture showed reduced expression of CD83 and CD1a, both markers of DC maturity. The co-stimulative molecules such as CD80 and CD86, as well as secreted IFN- $\gamma, \mathrm{IL}-12$, were also down regulated by MSC treatment, thus rendering T-cells anergic downwards. To distinguish cell-cell contact from cytokine secretion, they set up a transwell system with different $\mathrm{MSC} /$ monocyte ratios. The MSCs plated in the lower compartment were able to fully prevent monocytes from differentiation and maturation at a high $\mathrm{MSC} /$ monocyte ratio(1:10). It can thus be concluded that MSCs play the part of regulator throughout the immune response, including different phases, various cell types, and diverse modes of action.

Most recently, MSCs were found to act as immune-modulators, rather like a double-edged sword. The article published by W Li proposed that the degree of NO (nitric oxide) production elicited by pro-inflammatory cytokines in the surrounding environment could influence MSCs to be either potently immunosuppressive or highly immune-enhancing (65). While inducible nitric oxide synthase (iNOS) production was blocked, the immunosuppressive property of MSCs diminished and reverted to promote T-cell proliferation, as well as the delayed-type hypersensitivity response by their chemotactic effect on immunocytes. This immunoenhancing effect of MSCs might be attributed to chemokines such as CXCR3 (chemokine C-X-C motif receptor 3 ) and CCR5 (chemokine $\mathrm{C}-\mathrm{C}$ motif receptor 5 ) derived from MSCs. To some extent, this gained support from the evidence that iNOS ${ }^{-1}$ MSCs failed to promote 
proliferation of $\mathrm{CXCR}^{-/} \mathrm{CCR}^{-/}$splenocytes. These results highlight the importance of evaluating inflammation status and intervention with regard to iNOS/IDO levels before MSCs can be broadly applied for immunological disease in both rodent models and human clinical trials. Other than suboptimal timing and dose of administered MSCs, it might partially explain the reasons why the manipulation of MSCs in GVHD showed mixed results with some indicating an immunosuppressive potential and others not $(21,112)$.

\subsection{Angiogenic and arteriogenic factors}

It has been proven that angiogenic and arteriogenic support accounts for amelioration of coronary artery disease (CAD) following bone marrow cell transplantation $(88,89)$. Angiogenesis is evidenced by formation of a new blood network from the pre-existing capillaries by sprouting and proliferation, while arteriogenesis is demonstrated by the collateral enlargement and muscularization of small arterioles to form larger arteries (27). Angiogenesis is tightly regulated by a competitive balance of the angiopoietins and inhibitors, known as "angiogenic switch" (84). Only when the increasing cytokines and cell adhesion receptors that impel neovascularization reach a certain level and concentration in the locoregional environment can they incrementally initialize the process of angiogenesis. It has been reported that the HIF-1 (hypoxiainducible factor) signaling pathway can switch on this angiogenesis process in ischemic disease (122). HIF-1 is a nucleoprotein with transcription properties that regulates the expression of a variety of target genes with the ability to acclimatize and promote cell survival in an oxygen-deficient environment, including glycolytic enzymes that provide ATP for cell metabolism, and proangiogenetic factors such as VEGF, FGF, NO, IGF (insulin-like growth factor) $(28,43,75,99)$. It is only under hypoxic conditions that HIF-1 can be stabilized and activate expression of the downstream proteins. The transcriptional activation mediated by HIF-1 results in an escalating concentration of the biological cytokines that trigger the vascular endothelial cells to proliferate, sprout, migrate and infiltrate to develop new vasoganglion. Accompanied by pericytes, as well as optimal differentiation and apoptosis of the endothelial cells, the newborn vessels begin to form lumens. It is this physiological mechanism that led to the initiative to utilize MSCs for the treatment of ischemia: they express and produce VEGF, HGF, MCP1 (chemokine C-C motif ligand 2), and SDF1 (stromal cell-derived factor 1) that are critical for vascular network remodeling $(53,54)$. Several studies attempting to explore the 
potential of MSCs for vascular regeneration have consistently reported increasing capillary density and better collateral perfusion following MSC manipulation, although whether the secretion of cytokines represents the paramount mechanism of action remains under dispute $(40,49,61,78,82,107,109)$. In particular, a recent study by Feng Dong et al. concerning the SDF1:CXCR4 axis revealed that CXCR4 expression in CMCs was a necessity for the trophic effects generated by MSCs following left anterior descending artery (LAD) ligation (22). The researchers injected MSCs into wild type mice or conditional CMC-CXCR4 knockout mice post MI induction. They observed an increased number of CMCs undergoing apoptosis and decreased cardiac progenitor cell (CPC) recruitment in the absence of CMC-CXCR4 expression, leading to depletion of MSC-mediated functional restoration. This was despite equivalent levels of implanted MSC infusion and increases in capillary density. It is reasonable to conclude from these results that the protective and restorative benefits mediated by MSCs are partially due to angiogenesis factors that lead to increasing vascular density and recovery of blood supply in the ischemic area. Nonetheless the importance of coordination of the hibernating or susceptible cells in the vicinity cannot be underestimated.

\subsection{Anti-apoptotic factors}

To prevent programmed cell death, MSCs not only restore the microhemodynamics, but also synthesize and secrete proteins that are classic inhibitors of apoptosis, such as Bcl-2 (B-cell lymphoma 2), survivin, and Akt $(86,123)$. The ratio of $\mathrm{Bcl}-2$ to $\mathrm{Bax}$ (Bcl-2-associated $\mathrm{X}$ protein) determines the sensitivity of the cells to a pathological stimulus (87). The predominantly expressing $\mathrm{Bcl}-2$ will prevent the release of caspase activators, thus cells are less likely to respond to the apoptotic signaling, and vice versa (35). Tang et al. detected down-regulated Bax expression in the ischemic myocardium following autologous MSC transplantation (116). Zhang et al. showed lower expression of Bax, FAS (TNF receptor superfamily, member 6), and CASP3 (caspase 3 ) at both a transcriptional and translational level in MSC-CM treated LO2 (a human normal liver cell line) subjected to $\mathrm{H}_{2} \mathrm{O}_{2}$ challenge, a laboratory setting intended to mimic ischemic-reperfusion (IR) injury in liver, resulting in protection of hepatocytes against apoptosis (92). It is also worth noting that as well as the ability of MSCs to synthesize proteins that directly repress apoptosis, they are also able to secrete cytokines that either neutralize the apoptotic pathway or enhance survival. Gerber et al. established that VEGF could prevent serum starvation-induced apoptosis by upregulating $\mathrm{Bcl}-2$ expression in vascular endothelial cells (32). VEGF also participated in an anti-apoptotic process by 
phosphorylated activation of FAK (focal adhesion Kinase), a critical pro-survival signal that acts by suppressing p53-mediated apoptosis $(41,71,72)$. The bioactive molecules against apoptosis secreted by MSCs not only affect nearby cells, but also fulfill their own mission. Studies by Wang and colleagues showed that hypoxic preconditioning repressed the apoptotic index of MSCs by stabilizing mitochondrial membrane potential and elevating the secretion of VEGF and $\mathrm{BCl}-2$ (93).

\subsection{Anti-oxidative factors}

The concept of oxidative stress (OS) was derived from the free radical theory of Sohal et al. in their research on aging and life span $(90,110)$. OS is initiated by disequilibrium of oxidation and anti-oxidation in response to physiochemical or physiological stimuli. When an oxidative reaction prevails, the following process should occur: infiltration of inflammatory cells, release of protease, and accumulation of oxidative byproducts referred to as ROS (reactive oxygen species), including oxygen ions, oxygen free radical and peroxides. Insufficient or surplus ROS may give rise to pathogenesis known as ROS-related diseases, such as carcinogenesis, immune disorders, inflammation, neurodegeneration, or angiocardiopathy $(26,46,48,73)$. Studies by Shinya et al. highlighted the protective function of MSC-derived STC1 (stanniocalcin1) by reducing ROS-related apoptosis. STC1 also featured in another article with regard to its anti-oxidative activity in CMCs. This indicates that the successful harvest of MSCs in heart disease was mediated partially by releasing STC1 $(68,85)$. Another study described xenogenic MSC engraftment that ameliorated the redox environment in a LPS-induced acute lung injury (ALI) model by enhancing expression of anti-oxidative enzyme HO-1 (hemeoxygenase-1) and reducing expression of MDA (malondialdehyde), an indicator of lipid peroxidation (63). The enriched concentration of pro-inflammatory cytokines TNF- $\alpha$ (tumor necrosis factor $\alpha$ ), IL-1 $\beta$ (interleukin-1 $\beta$ ), IL-6 (interleukin-6), but not IL-10 (interleukin-10), existed in the MSC-treated group and may play a role in this modulatory activity. Studies by Zarjou et al. supported the importance of $\mathrm{HO}-1$ by the use of $\mathrm{HO}-1^{-1-} \mathrm{MSC}$, in which less effective production of SDF1, VEGF, and HGF was detected (133). With respect to ischemic-reperfusion (IR) injury, MSCs were beneficial; they encouraged expression of HO-1 in renal IR induced by cisplatin or surgery $(70,133)$. Another group who studied neurodegenerative dysfunction reported a similar "shield/barrier" effect conferred by MSCs on monoaminergic perikarya and monoamine neurotransmitter transporter function exposed to NO (nitric oxide) induced OS. They identified another trophic factor, GDNF (glial derived neurotrophic factor) 
(125). The operative molecules secreted by MSCs vary in different experimental settings, probably due to non-uniform ROS inductors leading to different levels of ROS production. Nonetheless it is evident that MSC therapy has an extensive influence on the redox context due to these anti-oxidative factors.

\subsection{Cell migration, homing/targeting and stimulation}

Several studies using different cell tracking approaches have revealed that following intravenous administration, MSCs are widely distributed to nonhematopoietic tissues, including the gastrointestinal tract, kidney, skin, lung, thymus, and liver. This suggests that MSCs patrol the body until triggered by what might be metaphorically compared to "criminal behavior" $(18,19)$. Indirect evidence supporting this hypothetical notion has been well documented in various disease models, in which MSCs showed faster mobilization and better retention at sites of injury following systemic or local intra-tissue infusion $(10,44,51,94)$. The inherent tumor-trophic migratory properties of MSCs have been employed as gene/drug carriers to deliver therapeutic, effective, targeted therapy to carcinomas and metastatic diseases (127). Thus, investigations oriented towards the motivation of this migration behavior proliferated. The intention was to maximize the therapeutic potential of MSCs by establishing a more efficient platform of stem cell homing and/or targeting. Several pathways or attractants have been discovered. Kitaori et al. demonstrated that inducible SDF1 expression in the periosteum of a live bone graft was required to recruit MSCs for endochondral bone repair (55). By neutralizing SDF1 with anti-SDF1 antibody or antagonizing CXCR4 with TF14016, new bone formation was significantly reduced following intravenous injection of MSCs. This suggests the involvement of SDF1:CXCR4 axis in MSC-mediated tissue repair and regeneration. Under hypoxic conditions, MSCs exhibited enhanced mobility towards SDF1 in a concentration-dependent manner, accompanied by elevated cellular CXCR4 expression (132). In accordance with the in vitro experiments, the in vivo study showed increased MSC retention in the infarct region 5 days after $\mathrm{MI}$, when ischemic-related SDF1 reached the fastigium. When cells were pre-treated with LY294002 (a reagent that selectively inhibits PI3K/Akt), a smaller number of implanted cells targeted the injured area with enlargement of the infarcted fibrotic area compared with non-treated cells. This indicated that the PI3K/Akt pathway was involved in the chemotactic response of MSCs to the SDF1:CXCR4 axis. In a separate but similar experiment, the LAD occlusioninduced SDF1 expression in the infarcted myocardium resulted in accumulation of bone marrow-derived cells delivered by intravenous injection (1). This time the author employed AMD3100, an antagonist of CXCR4, to confirm the instrumental role of the SDF1:CXCR4 signaling pathway in regard to stem cell 
homing. Another noteworthy finding in this study was that SDF1 alone could not trigger the grafted cells to migrate, indicating the requirement for another concomitant secretion or pathway stimulation. In addition, SDF1 serves as a chemo-attractant signal to the endogenous $\mathrm{CXCR}^{+}$stem cells. Otsuru's paper stated that the expression of SDF1 in vascular endothelial cells promoted migration of $\mathrm{CXCR}^{+}$bone marrow-derived osteoblast progenitor cells from circulating blood to the region of osteogenesis (91). In another study, Tang et al. reported that CM of genetically modified MSCs with VEGF expression containing more SDF1, achieved better left ventricular performance than unmodified MSCs by massive mobilization and homing of bone marrow stem cells and cardiac stem cells (115). While mounting evidence revealed that upregulated SDF1 is a required though not unique signal for better localization of stem cell targeting, other studies focused on the other side of this axis, that is, CXCR4. Contrary to expectations, forced expression of CXCR4 into the myocardium by direct gene transfer prior to $\mathrm{MI}$ surgery resulted in increased infiltration of inflammatory cells and apoptosis of CMCs (14). If the manipulation of CMC-CXCR4 is not beneficial as predicted, it is likely that CMCCXCR4 expression serves as an indication of CMCs that are in a self-protective state of reduced energy consumption, or even hibernating as a means of surviving the ischemic episode. The necessity of myocardial CXCR4 expression was analysed recently using a conditional CMC-CXCR4 null mouse model (22). In the CMC-CXCR4 null mice, increased numbers of CMCs underwent programmed cell death in the border zone following MI plus stem cell therapy. This phenomenon diminished in the absence of stem cell infusion. In addition, far more CPCs accumulated and localized in response to MSCs in the wild type mice compared with CMC-CXCR4 null mice. Consequent to this, the concept was proposed that CMC-CXCR4 expression is required in MSC-mediated cytoprotection and CPC recruitment. Based on these data, it is possible to decipher a reciprocal relationship between the cells, either endogenous or exogenous, and surrounding milieu regarding SDF1:CXCR4 binding in the presence of $\mathrm{MI}$ : the increasing MI-induced SDF1 in the infarct region helps to attract endogenous $\mathrm{CXCR}^{+}$stem cells, in addition to migration of exogenous MSCs to the lesion as a result of the increasing concentration of SDF1; the localized and stabilized distribution of stem cells then augments the SDF1 signal by synthesizing and releasing more SDF1; this process works as an amplifying hierarchy, within which CM-CXCR4 expression is required for the implanted MSCs to recruit cardiac stem cells.

In addition to chemotactic-like properties, MSCs also help revitalize endogenous stem cells to accumulate and proliferate. Using in situ 
chromosome Y FISH technique, Lin et al. distinguished male donor bone marrow cells from female host cells, and established that bone marrow cells accounted for only $11 \%$ of the proliferating epithelial cells in a kidney IR model. This suggests a regenerative capacity generated by the inherent hibernating stem via revitalization or rejuvenation (67). In the pig MI model, Ckit (v-kit Hardy-Zuckerman 4 feline sarcoma viral oncogene homolog) and Ki-67 (antigen identified by monoclonal antibody $\mathrm{Ki}-67$ ) were detected at the peri-infarct region in the MSC-treated group, implying endogenous stem cell recruitment and re-entry of CMCs to the cell cycle and duplicate status (6). MSC-CM were as able as MSCs to mobilize cardiac stem cells in the first 3 days, suggesting that the paracrine signaling accounted for part of the stem cell homing effects in the acute phase, though not comparable with what could be achieved from direct MSC delivery in long-term results (36). In addition to SDF1, other members of the MSC secretion pool, such as HGF and IGF, were also shown to enhance mobilization and proliferation of cardiac stem cells (120).

\section{Regulation of paracrine biology of MSCS}

Gnecchi's group reported approximately 650 transcripts that expressed differentially between Akt-MSCs and vector-MSCs. This suggests that genetic modification of MSCs by overexpression of one pivotal gene that acts as a "switch" might alter the profile of the released factors and thus maximize the therapeutic potential. Intense efforts have been made to hone MSCs and make them more effective and efficient. The paracrine effects should hold most appeal because of the wish to have an extensive, stable and lasting mode of action.

\subsection{Preconditioning of MSCS}

Gnecchi et al. testified that hypoxic treatment of the Akt-MSCs facilitated release of trophic factors such as VEGF, bFGF, HGF, IGF, and TB4 (34). The hypoxic Akt-MSCs-CM provided cytoprotection and induced spontaneous contraction of the ARVC (adult rat ventricular cardiomyocytes) when exposed to prolonged hypoxia. Other groups compared the secretome in normal and hypoxic conditions: most suggested that the contents of the concentrated 
medium of MSCs cultured in a hypoxic environment were superior. Chang et al. reported that both HGF and VEGF were elevated in the MSCs maintained in $0.5 \%$ oxygen for 24 hours (13). They then concentrated the medium and injected it into the rat TBI (traumatic brain injury) model every $12 \mathrm{~h}$ consecutively for 3 days, with consequent findings of increasing neurogenesis as well as alleviation of motor and cognitive dysfunction. Another group highlighted the fact that under normal physiological conditions, MSCs originate in areas of low oxygen concentration such as bone marrow. They thus need to accommodate themselves to the higher oxygenation that is present when they are isolated and expanded ex vivo (21\% oxygen) (103). They then need to immediately re-acclimatize to a hypoxic state when applied as a cell source for ischemic disease models. Subjecting MSCs to a premature hypoxic period may allow them a "buffering period" and thus improve their tissue regenerative potential. In this project, it was shown that pre-culturing MSCs in a low oxygen environment activated the Akt and CMET (met proto-oncogene, receptor of HGF) signaling pathway, contributing to enhanced neovascularization and stem cell homing in a surgical hind limb ischemia model. Another study by Lionel et al. also went some way to confirm that hypoxic preconditioning of MSCs promoted their survival capacity, and vascular and tissue reconstruction, albeit via a Wnt4 (wingless-related MMTV integration family, member 4)-dependent pathway (62).

In addition to physiological preconditioning, another feasible method may be cytokines/chemicals. Application of cytokine/chemicals by three different ways improved the therapeutic efficiency of MSCs: administration of cytokines/chemicals to MSCs prior to transplantation, aimed at optimizing the secretome with better migration towards the injured tissue; pretreatment at the site of injury, with the objective of attracting more stem cells for tissue repair; or simultaneous injection of cytokines/chemicals and MSCs. As an example, Yong et al. pretreated MSCs with IL-1 $\beta$ and TGF- $\beta$, and showed synergistic advantages of this combination on VEGF production, as well as functional restoration post MI (74). Cui et al. indirectly up-regulated SDF1:CXCR4 expression with a nitric oxide donor, DETA-NONOate. They demonstrated that preconditioning of the animal with DETA-NONOate 24 hours following middle cerebral artery occlusion promoted MSC engraftment. 
In Pons's study, VEGF and MSCs were co-injected to MI hearts, that then showed the expected congenerous improvement in stem cell mobilization and cardiac function (98).

\subsection{Genetic modification of MSCs}

Their ability to migrate towards damaged tissue makes MSCs the optimal vector for therapeutic agents. Gnecchi et al. not only defined the paracrine mechanism, but also demonstrated that genetically engineered MSCs with Akt expression were superior to vector-MSCs in many aspects $(33,34)$. Since then, many attempts have been made to equip MSCs with curative genes to aid functional recovery. $\mathrm{Li}$ et al. engineered MSCs with $\mathrm{BCl}-2$, and the modified cells presented better apoptotic tolerance, cell survival and more VEGF secretion than control MSCs (64). Other genetically engineered MSCs, including survivin, SDF1, CXCR4, HGF, PI3K, IGF, showed similar results of improving angiogenesis, LVEF, endogenous stem cell recruitment, contractile function, and reducing LV remodeling effects $(23,24,57,111,114,126)$. Most of these selected genes are considered to be trophic factors secreted by physiological MSCs, or possess the ability to activate Akt signaling directly or indirectly, based on maintaining the fundamental characteristics of MSCs and safety concern. Genetic manipulation could improve cell survival and control the MSC secretome by engineering the gene of interest; nonetheless overexpression could bring unexpected effects, either from the delivering approach or the targeting genes. For example, over expressing of bFGF or PDGF- $\beta$ (platelet-derived growth factor $\beta$ ) lead to highly proliferating MSCs and increases in osteogenesis, while upregulation of TGF- $\beta 1$ hindered both osteogenic and adipogenic differentiation (25). It should nonetheless be noted that while the genetically modified MSCs showed enhanced therapeutic efficacy, a very stringent evaluation of their physiological characteristics with regard to safety and undesired effects is required prior to their application in clinical trials .

\section{Important Paracrine factors of MSCs in modulation of tissue repairs}

\subsection{Paracrine factors- activated MSCs in immunomodulation}


Mesenchymal stem cells have the ability to suppress the immune response and can even induce immune tolerance in certain conditions through cell to cell contact and soluble factors. An increasing number of studies have suggested that the soluble factors of MSCs are a key requirement of their immune regulatory properties $(29,113,128)$. Liu et al. demonstrated that the immunogenicity of MSCs was heightened during the increasing passage number and could not suppress lymphocyte proliferation in vitro (69). Nonetheless, soluble factors collected from the co-culture of MSCs and lymphocytes could suppress lymphocyte proliferation without the need for cell to cell contact. Ren et al. found that the pro-inflammatory cytokine-activated MSCs could secrete chemokines to recruit lymphocytes (101). Then the MSCs concentrated their action on the localized lymphocytes by secreting TGF- $\beta$ and NO with two effects: inhibition of proliferation and promotion of apoptosis. Yang et al. reported that soluble factors from the culture supernatant of MSCs could suppress T cell proliferation, in which IL-10 and IDO played important roles (131). TGF- $\beta$, HGF, Prostaglandin E2, HLA-G5, IL-6, CCL2, CCL5 and other chemokines have also shown that the paracrine mechanism of MSCs can modulate regulatory T cells (Tregs) and the immune response $(38,83,104,117)$.

Polchert et al. found that IFN- $\gamma$ pre-treated MSCs reduced GvHD more efficiently than the MSCs without IFN- $\gamma$ pre-treatment (97). It has been suggested that the immunomodulatory ability of MSCs is activated by 
inflammatory factors secreted by lymphocytes. In the acute HvGR (host versus graft reaction) and GvHR, the activated Th1 cell releases cytokines such as IL-2 and IFN- $\gamma$ to promote lymphocyte proliferation and amplify the immune response. Alternately, these pro-inflammatory cytokines also reverse the immunosuppressive properties of MSCs, which release soluble factors in turn to suppress HvGR and GvHR.

MSCs have demonstrated their practical application in terms of HvGR and GvHR in vivo. Aksu et al. reported that autologous MSCs could limit the toxicity of allogeneic bone marrow transplantation and delay GvHD onset when coinfused four-times with unmodified donor bone marrow (3). Ge et al. found that infusion of MSCs with rapamycin achieved long-term cardiac allograft survival by inducing Tregs that could suppress the acute rejection response and induce immune tolerance (31). Other studies have demonstrated that soluble factors such as TGF- $\beta$ can promote the viability of regulatory cells, indicating an indirect pattern to modulate the immune response $(129,117)$. Despite these advances, the use of the paracrine effects of activated MSCs to treat organ transplantation and GvHD remains in its infancy and further animal and human studies are required.

\subsection{Paracrine factors and cardiovascular diseases}

MSCs have emerged as a very promising cell type for the treatment of cardiovascular disease both in small animal studies and large animal models $(15,52,66,77,95,105,119,131)$. The exact extent to which these cells form new cardiac myocytes and improve cardiac function nonetheless remains highly controversial $(7,80)$. The disproportion between tremendous functional recovery and low rates of cell engraftment and persistence suggests an indirect primary mechanism other than structural integration of transplanted cells into ischemic myocardium. Thus the ability of MSCs to produce a variety of trophic 
and immunomodulatory factors that can directly promote cell survival and reduce inflammation post-transplantation has attracted great attention. $(7,33,80,118)$. While Gnecchi and Kinnaird have already focused on the cardioprotective properties of MSCs via a paracrine effect, the current focus is to locate the most efficient factors with high tissue specificity, or optimal design with synergistic effects to maximize myocardial survival post infarction. For instance, Gnecchi's research identified Sfrp2 (secreted frizzled related protein 2) as the most dramatically up-regulated protein (100 fold in transcriptional level) in the Akt-MSCs. As an extension of this research, He W and others confirmed the tissue regenerative capacity of Sfrp2 by simple administration to the infarcted areas $(4,37,79)$. Zhang et al. proposed that combined treatment with Wnt11 (wingless-type MMTV integration site family, member 11) and BMP-2 (bone morphogenetic protein 2) increased the cardiomyogenic potential of MSCs and raised the possibility that preconditioning MSCs with inducible factors might augment the transdifferentiation odds (135). Indeed, the paracrine mechanism of MSCs facilitates the discovery and discrimination of the most powerful soluble factors, and above all, makes possible the broader future application and conversion of these factors into novel therapeutic applications for clinical offthe-shelf therapy. Kanki et al. showed intracoronary injection of SDF-1 could 
improve ventricular function in experimental ischemia/reperfusion injury even 3 hours after the onset of ischemia (50). In a clinical trial of 178 patients, highdose VEGF administration improved treadmill tests, angina class, and quality of life assessments at day 120 (39). Nonetheless not all the beneficial cytokines identified from the MSC-CM (conditional medium of mesenchymal stem cells) achieved satisfactory consequences as expected. For example, G-CSF (granulocyte-colony stimulating factor) alone did not yield any encouraging alteration in $\mathrm{MI}$ patients, despite its definite safety and feasibility $(102,121)$. The reasons for this contradiction might be varied: the dose, timing and delivery method need to be optimized; the combination of cytokines at different concentrations and time points might heighten the synergistic effects. Though these issues still wait to be addressed, it is worth noting that non-cellbased alternative cytokine delivery does circumvent the major drawbacks such as quantification control, immunological rejection, concerns about infection and carcinogenesis, compared with direct stem cell injection. It also facilitates the establishment and optimization of curative standard.

\section{Exosome and mitochondrial transfer for tissue repair}

Tim and colleagues demonstrated that intravenous and intracoronary injection of MSC-CM significantly restored ventricular performance in a porcine model of IR injury (118). Of note, only the CM containing products $>1000 \mathrm{kDa}$ $(100-220 \mathrm{~nm})$ contributed to the cytoprotective effects, implying that the paracrine signaling might function as a large complex rather than a single small 
molecule. Co-immunoprecipitation by ultracentrifugation identified that these particles contain plasma membrane phospholipids such as cholesterol, sphingomyelin, and phosphatidylcholine, as well as exosome-associated proteins CD81, CD9, and Alix. Electron microscopic examination of the size and morphology revealed that this group of bioactive particles released by MSCs were exosomes (59). The purified exosomes at a dose of 0.4ug were then delivered to an IR injury 5 minutes prior to reperfusion, and showed comparable capacity in reducing infarct size to that of a 3.0ug dose of MSC-CM. Proteomics, transcriptomics, miRNA array or other high-throughput technologies are practical to exploit the content in the vesicles. With proteomic profiling using mass spectrometry and antibody array, Lai et al. reported 857 proteins in the exosome proteome, in which 205 proteasome was determined as the main contributor to cardioprotection by reducing the amount of misfolded proteins during acute $\mathrm{MI}(60)$. It appears that MSCs are working in a more intelligent and efficient way than we expect by encapsulating functional proteins or regulatory RNAs into exosomes, via whose phospholipid envelop a rapid intracellular delivery pathway is created, thus allowing MSCs to mount an early response to stimuli.

Contrary to this, the most recent work by Islam et al. provided in vivo evidence of mitochondrial transfer from MSCs to host cells in the ALI model induced by LPS (lipopolysaccharide) instillation (42). With live imaging, they observed instilled MSCs attached to the alveoli and intercellular dye exchange began, suggesting the involvement of gap junctional channels (GJCs). FRAP (fluorescence recovery after photobleaching) occurred in alveolus-attached MSCs, affirming the existence of GJCs. The FRAP could be blocked by a nonspecific GJC blocker or the specific connexin43 (Cx43) inhibitor, providing further reverse proof of the involvement of GJCs and $\mathrm{Cx} 43$ in cell-cell contact between MSCs and the alveolar epithelium. The expression of GJC-competent $\mathrm{Cx} 43$ was indispensable to mediate a successful mitochondrial transfer, supported by the evidence that either mutant $\mathrm{Cx} 43$ or ablation of $\mathrm{Cx} 43$ led to failure of GJC formation. The internalized mitochondria acted functionally by increasing the ATP concentration in the recipient pulmonary alveoli, leading to bioenergetic restoration and protection in the acute phase of lung injury. Nevertheless, this successful delivery also compromised the energy of MSCs 
with a resultant decrease in other cell behaviors that benefit the surrounding or remote areas, such as secretion capability, migration ability, and exosome packaging. It was nevertheless certain that MSCs played multiple roles, trying to repair or normalize the tissue during disease emergencies, though the combined or neutralized effects and the proportions of each substation among these different modes of action require further investigation.

\section{Perspective}

It is undisputable that MSC therapy contributes to restoration of structural integrity and functionality of damaged tissue, but their fundamental and detailed biological mechanisms require further elucidation. The many effects of MSCs, including trans-differentiation, cell-fusion, paracrine, exosome secretion and mitochondrial transfer, each have drawbacks that need to be addressed before maximal benefit is obtained: trans-differentiation and cell fusion seem to occur in too low a frequency to account for the meaningful improvement; exosome secretion and mitochondrial transfer faces the problem of finding a robust and scalable cell source with sufficient quantity and quality to generate exosome encapsulation and energy transportation. With regard to paracrine actions, the limitations must not be overlooked. For instance, some cytokines or chemokines released from MSCs may be harmful, such as TNF- $\alpha$ (tumor necrosis factor $\alpha$ ) and IL-6. This may explain the modest benefit of MSC transplantation observed in clinical trials (124). Nonetheless mounting evidence suggests that the secretion profile can be readily improved by preconditioning or genetic manipulation. Furthermore, the paracrine action provides the possibility to apply one trophic factor alone, or combined as a cocktail therapy for disease-orientated treatment. The advantage of MSCbased therapy is that it can maintain a sustainable moderate release and concentration of the trophic factors that might be varied according to diverse microenvironments and situations. It seems that these cells are working smartly and systematically, to adapt themselves in harsh disease conditions, with the aim restoring physiological status. Thus, the paracrine effects of MSCs hold great promise as a controllable, manageable and feasible route, by which the transition from bench to bedside becomes more feasible in the near future. 


\section{Acknowledgements}

This study was partly supported by grants from the GRF/RGC (HKU $722510 M$ to Q Lian), National Natural Science Grant of China (81170896), and Small project funding from The University of Hong Kong (201111159183 to Q Lian).

\section{Authors declare no conflicts of Interest.}

\section{References}

1. Abbott, J. D.; Huang, Y.; Liu, D.; Hickey, R.; Krause, D. S.; Giordano, F. J. Stromal cell-derived factor-1alpha plays a critical role in stem cell recruitment to the heart after myocardial infarction but is not sufficient to induce homing in the absence of injury. Circulation. 110(21):3300-3305; 2004.

2. Adutler-Lieber, S.; Ben-Mordechai, T.; Naftali-Shani, N.; Asher, E.; Loberman, D.; Raanani, E.; Leor, J. Human Macrophage Regulation Via Interaction With Cardiac Adipose Tissue-Derived Mesenchymal Stromal Cells. J. Cardiovasc. Pharmacol. Ther. 18(1):78-86; 2013.

3. Aksu, A. E.; Horibe, E.; Sacks, J.; Ikeguchi, R.; Breitinger, J.; Scozio, M.; Unadkat, J.; Feili-Hariri, M. Coinfusion of donor bone marrow with host mesenchymal stem cells treats GVHD and promotes vascularized skin allograft survival in rats. Clin. Immunol. 127(3):348-358; 2008.

4. Alfaro, M. P.; Vincent, A.; Saraswati, S.; Thorne, C. A.; Hong, C. C.; Lee, E.; Young, P. P. sFRP2 suppression of bone morphogenic protein (BMP) and Wnt signaling mediates mesenchymal stem cell (MSC) selfrenewal promoting engraftment and myocardial repair. J. Biol. Chem. 285(46):35645-35653; 2010.

5. Alvarez-Dolado, M.; Pardal, R.; Garcia-Vardugo, J. M.; Fike, J. R.; Lee, H. O.; Pfeffer, K.; Lois, C.; Morrison, S. J.; Alvarez-Buylla, A. Fusion of bone-marrow-derived cells with Purkinje neurons, cardiomyocytes and hepatocytes. Nature. 425(6961):968-973; 2003.

6. Amado, L. C.; Saliaris, A. P.; Schuleri, K. H.; St John, M.; Xie, J. S.; Cattaneo, S.; Durand, D. J.; Fitton, T.; Kuang, J. Q.; Stewart, G. ;Lehrke, S.; Baumgartner, W. W.; Martin, B. J.; Heldman, A. W.; Hare, J. M. Cardiac repair with intramyocardial injection of allogeneic mesenchymal stem cells after myocardial infarction. Proc. Natl. Acad. Sci. U.S.A. 102(32):11474-11479; 2005.

7. Amsalem, Y.; Mardor, Y.; Feinberg, M. S.; Landa, N.; Miller, L.; Daniels, D.; Ocherashvilli, A.; Holbova, R.; Yosef, O.; Barbash, I. M.; Leor, J. Iron-oxide labeling and outcome of transplanted mesenchymal stem cells in the infarcted myocardium. Circulation. 116(11 Suppl):I38-45; 2007.

8. Arthur, A.; Zannettino, A.; Gronthos, S. The therapeutic applications of multipotential mesenchymal/stromal stem cells in skeletal tissue repair. J. Cell. Physiol. 218(2):237-245; 2009.

9. Asanuma, H.; Meldrum, D. R.; Meldrum, K. K. Therapeutic applications of mesenchymal stem cells to repair kidney injury. J. Urol. 184(1):26-33; 2010. 
10. Assis, A. C.; Carvalho, J. L.; Jacoby, B. A.; Ferreira, R. L.; Castanheira, P.; Diniz, S. O.; Cardoso, V. N.; Goes, A. M.; Ferreira, A. J. Time-dependent migration of systemically delivered bone marrow mesenchymal stem cells to the infarcted heart. Cell Transplant. 19(2):219-230; 2010.

11. Bartholomew, A.; Sturgeon, C.; Siatskas, M.; Ferrer, K.; Mclntosh, K.; Patil, S.; Hardy, W.; Devine, S.; Ucker, D.; Deans, R.; Moseley, A.; Hoffman, R. Mesenchymal stem cells suppress lymphocyte proliferation in vitro and prolong skin graft survival in vivo. Exp. Hematol. 30(1):42-48; 2002.

12. Becker, A. J.; Mc, C. E.; Till, J. E. Cytological demonstration of the clonal nature of spleen colonies derived from transplanted mouse marrow cells. Nature. 197:452-454; 1963.

13. Chang, C. P.; Chio, C. C.; Cheong, C. U.; Chao, C. M.; Cheng, B. C.; Lin, M. T. Hypoxic preconditioning enhances the therapeutic potential of the secretome from cultured human mesenchymal stem cells in experimental traumatic brain injury. Clin. Sci. 124(3):165-176; 2013.

14. Chen, J.; Chemaly, E.; Liang, L.; Kho, C.; Lee, A.; Park, J.; Altman, P.; Schecter, A. D.; Hajjar, R. J.; Tarzami, S. T. Effects of CXCR4 gene transfer on cardiac function after ischemia-reperfusion injury. Am. J. Pathol. 176(4):1705-1715; 2010.

15. Chen, S. L.; Fang, W. W.; Ye, F.; Liu, Y. H.; Qian, J.; Shan, S. J.; Zhang, J. J.; Chunhua, R. Z.; Liao, L. M.; Lin, S.; Sun, J. P. Effect on left ventricular function of intracoronary transplantation of autologous bone marrow mesenchymal stem cell in patients with acute myocardial infarction. Am. J. Pathol. 94(1):92-95; 2004.

16. Cselenyak, A.; Pankotai, E.; Horvath, E. M.; Kiss, L.; Lacza, Z. Mesenchymal stem cells rescue cardiomyoblasts from cell death in an in vitro ischemia model via direct cell-to-cell connections. Bmc Cell Biol. 11:29; 2010.

17. Dayan, V.; Yannarelli, G.; Billia, F.; Filomeno, P.; Wang, X. H.; Davies, J. E.; Keating, A. Mesenchymal stromal cells mediate a switch to alternatively activated monocytes/macrophages after acute myocardial infarction. Basic Res. Cardiol. 106(6):1299-1310; 2011.

18. Deak, E.; Seifried, E.; Henschler, R. Homing pathways of mesenchymal stromal cells (MSCs) and their role in clinical applications. Int. Rev. Immunol. 29(5):514-529; 2010.

19. Devine, S. M.; Cobbs, C.; Jennings, M.; Bartholomew, A.; Hoffman, R. Mesenchymal stem cells distribute to a wide range of tissues following systemic infusion into nonhuman primates. Blood. 101(8):2999-3001; 2003.

20. Di Nicola, M.; Carlo-Stella, C.; Magni, M.; Milanesi, M.; Longoni, P. D.; Matteucci, P.; Grisanti, S.; Gianni, A. M. Human bone marrow stromal cells suppress T-lymphocyte proliferation induced by cellular or nonspecific mitogenic stimuli. Blood. 99(10):3838-3843; 2002.

21. Djouad, F.; Fritz, V.; Apparailly, F.; Louis-Plence, P.; Bony, C.; Sany, J.; Jorgensen, C.; Noel, D. Reversal of the immunosuppressive properties of mesenchymal stem cells by tumor necrosis factor alpha in collageninduced arthritis. Arthritis Rheum. 52(5):1595-1603; 2005.

22. Dong, F.; Harvey, J.; Finan, A.; Weber, K.; Agarwal, U.; Penn, M. S. Myocardial CXCR4 expression is required for mesenchymal stem cell mediated repair following acute myocardial infarction. Circulation. 126(3):314-324; 2012.

23. Eun, L. Y.; Song, B. W.; Cha, M. J.; Song, H.; Kim, I. K.; Choi, E.; Chang, W.; Lim, S.; Choi, E. J.; Ham, O.; Lee, S. Y.; Byun, K. H.; Jang, Y.; Hwang, K. C. Overexpression of phosphoinositide-3-kinase class II alpha 
enhances mesenchymal stem cell survival in infarcted myocardium. Biochem. Biophys. Res. Commun. 402(2):272-279; 2010.

24. Fan, L.; Lin, C.; Zhuo, S.; Chen, L.; Liu, N.; Luo, Y.; Fang, J.; Huang, Z.; Lin, Y.; Chen, J. Transplantation with survivin-engineered mesenchymal stem cells results in better prognosis in a rat model of myocardial infarction. Eur. J. Heart Fail. 11(11):1023-1030; 2009.

25. Fierro, F. A.; Kalomoiris, S.; Sondergaard, C. S.; Nolta, J. A. Effects on proliferation and differentiation of multipotent bone marrow stromal cells engineered to express growth factors for combined cell and gene therapy. Stem cells. 29(11):1727-1737; 2011.

26. Fisher, A. B. Reactive oxygen species and cell signaling with lung ischemia. Undersea Hyperb. Med. 31(1):97-103; 2004

27. Folkman, J. Tumor angiogenesis: therapeutic implications. N. Engl. J. Med. 285(21):1182-1186; 1971.

28. Forsythe, J. A.; Jiang, B. H.; Iyer, N. V.; Agani, F.; Leung, S. W.; Koos, R. D.; Semenza, G. L. Activation of vascular endothelial growth factor gene transcription by hypoxia-inducible factor 1. Mol. Cell. Biol. 16(9):4604-4613; 1996.

29. Fu, Q. L.; Chow, Y. Y.; Sun, S. J.; Zeng, Q. X.; Li, H. B.; Shi, J. B.; Sun, Y. Q.; Wen, W.; Tse, H. F.; Lian, Q.; Xu, G. Mesenchymal stem cells derived from human induced pluripotent stem cells modulate T-cell phenotypes in allergic rhinitis. Allergy. 67(10):1215-1222; 2012.

30. Gatti, S.; Bruno, S.; Deregibus, M. C.; Sordi, A.; Cantaluppi, V.; Tetta, C.; Camussi, G. Microvesicles derived from human adult mesenchymal stem cells protect against ischaemia-reperfusion-induced acute and chronic kidney injury. Nephrol. Dial. Transplant. 26(5):1474-1483; 2011.

31. Ge, W.; Jiang, J.; Baroja, M. L.; Arp, J.; Zassoko, R.; Liu, W.; Bartholomew, A.; Garcia, B.; Wang, H. Infusion of mesenchymal stem cells and rapamycin synergize to attenuate alloimmune responses and promote cardiac allograft tolerance. Am. J. Transplant. 9(8):1760-1772; 2009.

32. Gerber, H. P.; Dixit, V.; Ferrara, N. Vascular endothelial growth factor induces expression of the antiapoptotic proteins Bcl-2 and A1 in vascular endothelial cells. J. Biol. Chem. 273(21):13313-13316; 1998.

33. Gnecchi, M.; He, H.; Liang, O. D.; Melo, L. G.; Morello, F.; Mu, H.; Noiseux, N.; Zhang, L.; Pratt, R. E.; Ingwall, J. S.; Dzau V. J. Paracrine action accounts for marked protection of ischemic heart by Akt-modified mesenchymal stem cells. Nat. Med. 11(4):367-368; 2005.

34. Gnecchi, M.; He, H.; Noiseux, N.; Liang, O. D.; Zhang, L.; Morello, F.; Mu, H.; Melo, L. G.; Pratt, R. E.; Ingwall, J. S.; Dzau, V. J. Evidence supporting paracrine hypothesis for Akt-modified mesenchymal stem cell-mediated cardiac protection and functional improvement. FASEB J. 20(6):661-669; 2006.

35. Green, D. R.; Reed, J. C. Mitochondria and apoptosis. Science. 281(5381):1309-1312; 1998.

36. Hatzistergos, K. E.; Quevedo, H.; Oskouei, B. N.; Hu, Q.; Feigenbaum, G. S.; Margitich, I. S.; Mazhari, R.; Boyle, A. J.; Zambrano, J. P.; Rodriguez, J. E.; Dulce, R.; Pattany, P. M.; Valdes, D.; Revilla, C.; Heldman, A. W.; McNiece, I.; Hare, J. M. Bone marrow mesenchymal stem cells stimulate cardiac stem cell proliferation and differentiation. Circ. Res. 107(7):913-922; 2010. 
37. He, W.; Zhang, L.; Ni, A.; Zhang, Z.; Mirotsou, M.; Mao, L.; Pratt, R. E.; Dzau, V. J. Exogenously administered secreted frizzled related protein 2 (Sfrp2) reduces fibrosis and improves cardiac function in a rat model of myocardial infarction. Proc. Natl. Acad. Sci. U.S.A. 107(49):21110-21115; 2010.

38. Hegyi, B.; Kudlik, G.; Monostori, E.; Uher, F. Activated T-cells and pro-inflammatory cytokines differentially regulate prostaglandin E2 secretion by mesenchymal stem cells. Biochem. Biophys. Res. Commun. 419(2):215-220; 2012.

39. Henry, T. D.; Annex, B. H.; McKendall, G. R.; Azrin, M. A.; Lopez, J. J.; Giordano, F. J.; Shah, P. K.; Willerson, J. T.; Benza, R. L.; Berman, D. S. Gibson, C. M.; Bajamonde, A.; Rundle, A. C.; Fine, J.; McCluskey, E. R.; Viva Investigators. The VIVA trial: Vascular endothelial growth factor in Ischemia for Vascular Angiogenesis. Circulation. 107(10):1359-1365; 2003.

40. Huang, N. F.; Lam, A.; Fang, Q.; Sievers, R. E.; Li, S.; Lee, R. J. Bone marrow-derived mesenchymal stem cells in fibrin augment angiogenesis in the chronically infarcted myocardium. Regen. Med. 4(4):527-538; 2009.

41. Ilic, D.; Almeida, E. A.; Schlaepfer, D. D.; Dazin, P.; Aizawa, S.; Damsky, C. H. Extracellular matrix survival signals transduced by focal adhesion kinase suppress p53-mediated apoptosis. J. Cell Biol. 143(2):547-560; 1998.

42. Islam, M. N.; Das, S. R.; Emin, M. T.; Wei, M.; Sun, L.; Westphalen, K.; Rowlands, D. J.; Quadri, S. K.; Bhattacharya, S.; Bhattacharya, J. Mitochondrial transfer from bone-marrow-derived stromal cells to pulmonary alveoli protects against acute lung injury. Nat. Med. 18(5):759-765; 2012.

43. Jiang, B. H.; Rue, E.; Wang, G. L.; Roe, R.; Semenza, G. L. Dimerization, DNA binding, and transactivation properties of hypoxia-inducible factor 1. J. Biol. Chem. 271(30):17771-17778; 1996.

44. Jiang, W.; Ma, A.; Wang, T.; Han, K.; Liu, Y.; Zhang, Y.; Dong, A.; Du, Y.; Huang, X.; Wang, J.; Lei, X.; Zheng, $X$. Homing and differentiation of mesenchymal stem cells delivered intravenously to ischemic myocardium in vivo: a time-series study. Pflugers Arch. 453(1):43-52; 2006.

45. Jiang, X. X.; Zhang, Y.; Liu, B.; Zhang, S. X.; Wu, Y.; Yu, X. D.; Mao, N. Human mesenchymal stem cells inhibit differentiation and function of monocyte-derived dendritic cells. Blood. 105(10):4120-4126; 2005.

46. Kahles, T.; Luedike, P.; Endres, M.; Galla, H. J.; Steinmetz, H.; Busse, R.; Neumann-Haefelin, T.; Brandes, R. P. NADPH oxidase plays a central role in blood-brain barrier damage in experimental stroke. Stroke. 38(11):3000-3006; 2007.

47. Kajstura, J.; Rota, M.; Whang, B.; Cascapera, S.; Hosoda, T.; Bearzi, C.; Nurzynska, D.; Kasahara, H.; Zias, E.; Bonafe, M.; Nadal-Ginard, B.; Torella, D.; Nascimbene, A.; Quaini, F.; Urbanek, K.; Leri, A.; Anversa, P. Bone marrow cells differentiate in cardiac cell lineages after infarction independently of cell fusion. Circ. Res. 96(1):127-137; 2005.

48. Kamata, T. Roles of Nox1 and other Nox isoforms in cancer development. Cancer Sci. 100(8):1382-1388; 2009.

49. Kamihata, H.; Matsubara, H.; Nishiue, T.; Fujiyama, S.; Tsutsumi, Y.; Ozono, R.; Masaki, H.; Mori, Y.; Iba, O.; Tateishi, E.; Kosaki, A.; Shintani, S.; Murohara, T.; Imaizumi, T.; Iwasaka, T. Implantation of bone marrow mononuclear cells into ischemic myocardium enhances collateral perfusion and regional function via side supply of angioblasts, angiogenic ligands, and cytokines. Circulation. 104(9):1046-1052; 2001. 
50. Kanki, S.; Segers, V. F.; Wu, W.; Kakkar, R.; Gannon, J.; Sys, S. U.; Sandrasagra, A.; Lee, R. T. Stromal cellderived factor-1 retention and cardioprotection for ischemic myocardium. Circ. Heart Fail. 4(4):509-518; 2011.

51. Kawada, H.; Fujita, J.; Kinjo, K.; Matsuzaki, Y.; Tsuma, M.; Miyatake, H.; Muguruma, Y.; Tsuboi, K.; Itabashi, Y.; Ikeda, Y.; Ogawa, S.; Okano, H.; Hotta, T.; Ando, K.; Fukuda, K. Nonhematopoietic mesenchymal stem cells can be mobilized and differentiate into cardiomyocytes after myocardial infarction. Blood. 104(12):3581-3587; 2004.

52. Kim, S. W.; Han, H.; Chae, G. T.; Lee, S. H.; Bo, S.; Yoon, J. H.; Lee, Y. S.; Lee, K. S.; Park, H. K.; Kang, K. S. Successful stem cell therapy using umbilical cord blood-derived multipotent stem cells for Buerger's disease and ischemic limb disease animal model. Stem Cells. 24(6):1620-1626; 2006.

53. Kinnaird, T.; Stabile, E.; Burnett, M. S.; Epstein, S. E. Bone-marrow-derived cells for enhancing collateral development: mechanisms, animal data, and initial clinical experiences. Circ. Res. 95(4):354-363; 2004.

54. Kinnaird, T.; Stabile, E.; Burnett, M. S.; Shou, M.; Lee, C. W.; Barr, S.; Fuchs, S.; Epstein, S. E. Local delivery of marrow-derived stromal cells augments collateral perfusion through paracrine mechanisms.

Circulation. 109(12):1543-1549; 2004

55. Kitaori, T.; Ito, H.; Schwarz, E. M.; Tsutsumi, R.; Yoshitomi, H.; Oishi, S.; Nakano, M.; Fujii, N.; Nagasawa, T.; Nakamura, T. Stromal cell-derived factor 1 /CXCR4 signaling is critical for the recruitment of mesenchymal stem cells to the fracture site during skeletal repair in a mouse model. Arthritis Rheum. 60(3):813-823; 2009.

56. Kong, D.; Melo, L. G.; Gnecchi, M.; Zhang, L.; Mostoslavsky, G.; Liew, C. C.; Pratt, R. E.; Dzau, V. J. Cytokineinduced mobilization of circulating endothelial progenitor cells enhances repair of injured arteries. Circulation. 110(14):2039-2046; 2004.

57. Kucic, T.; Copland, I. B.; Cuerquis, J.; Coutu, D. L.; Chalifour, L. E.; Gagnon, R. F.; Galipeau, J. Mesenchymal stromal cells genetically engineered to overexpress IGF-I enhance cell-based gene therapy of renal failureinduced anemia. Am. J. Physiol. Renal Physiol. 295(2):F488-496; 2008.

58. Laflamme, M. A.; Zbinden, S.; Epstein, S. E.; Murry, C. E. Cell-based therapy for myocardial ischemia and infarction: pathophysiological mechanisms. Annu. Rev. Pathol. 2:307-339; 2007.

59. Lai, R. C.; Arslan, F.; Lee, M. M.; Sze, N. S.; Choo, A.; Chen, T. S.; Salto-Tellez, M.; Timmers, L.; Lee, C. N.; El Oakley, R. M.; Pasterkamp, G.; de Kleijn, D. P.; Lim, S. K. Exosome secreted by MSC reduces myocardial ischemia/reperfusion injury. Stem Cell Res. 4(3):214-222; 2010.

60. Lai, R. C.; Tan, S. S.; Teh, B. J.; Sze, S. K.; Arslan, F.; de Kleijn, D. P.; Choo, A.; Lim, S. K. Proteolytic Potential of the MSC Exosome Proteome: Implications for an Exosome-Mediated Delivery of Therapeutic Proteasome. Int. J. Proteomics. 2012:971907; 2012.

61. Lee, B. C.; Hsu, H. C.; Tseng, W. Y.; Chen, C. Y.; Lin, H. J.; Ho, Y. L.; Su, M. J.; Chen, M. F. Cell therapy generates a favourable chemokine gradient for stem cell recruitment into the infarcted heart in rabbits. Eur. J. Heart Fail. 11(3):238-245; 2009.

62. Leroux, L.; Descamps, B.; Tojais, N. F.; Seguy, B.; Oses, P.; Moreau, C.; Daret, D.; Ivanovic, Z.; Boiron, J. M.; Lamaziere, J. M.; Dufourcq, P.; Couffinhal, T.; Duplaa, C. Hypoxia preconditioned mesenchymal stem cells improve vascular and skeletal muscle fiber regeneration after ischemia through a Wnt4-dependent pathway. Mol. Ther. 18(8):1545-1552; 2010. 
63. Li, J.; Li, D.; Liu, X.; Tang, S.; Wei, F. Human umbilical cord mesenchymal stem cells reduce systemic inflammation and attenuate LPS-induced acute lung injury in rats. J. Inflamm (Lond). 9(1):33; 2012.

64. Li, W.; Ma, N.; Ong, L. L.; Nesselmann, C.; Klopsch, C.; Ladilov, Y.; Furlani, D.; Piechaczek, C.; Moebius, J. M.; Lutzow, K.; Lendlein, A.; Stamm, C.; Li, R. K.; Steinhoff, G. Bcl-2 engineered MSCs inhibited apoptosis and improved heart function. Stem Cells. 25(8):2118-2127; 2007.

65. Li, W.; Ren, G.; Huang, Y.; Su, J.; Han, Y.; Li, J.; Chen, X.; Cao, K.; Chen, Q.; Shou, P.; Zhang, L.; Yuan, Z. R.; Roberts, A. I.; Shi, S.; Le, A. D.; Shi, Y. Mesenchymal stem cells: a double-edged sword in regulating immune responses. Cell Death Differ. 19(9):1505-1513; 2012.

66. Lian, Q. Z.; Zhang, Y. L.; Zhang, J. Q.; Zhang, H. K.; Wu, X. G.; Zhang, Y.; Lam, F. F. Y.; Kang, S.; Xia, J. C.; Lai, W. H.; Au, K. W.; Chow, Y. Y.; Siu, C. W.; Lee, C. N.; Tse, H. F. Functional Mesenchymal Stem Cells Derived From Human Induced Pluripotent Stem Cells Attenuate Limb Ischemia in Mice. Circulation. 121(9):1113$1123 ; 2010$.

67. Lin, F.; Moran, A.; Igarashi, P. Intrarenal cells, not bone marrow-derived cells, are the major source for regeneration in postischemic kidney. J. Clin. Invest. 115(7):1756-1764; 2005.

68. Liu, D.; Huang, L.; Wang, Y.; Wang, W.; Wehrens, X. H.; Belousova, T.; Abdelrahim, M.; DiMattia, G.; Sheikh-Hamad, D. Human stanniocalcin-1 suppresses angiotensin II-induced superoxide generation in cardiomyocytes through UCP3-mediated anti-oxidant pathway. PLoS ONE. 7(5):e36994; 2012.

69. Liu, H.; Lu, K.; MacAry, P. A.; Wong, K. L.; Heng, A.; Cao, T.; Kemeny, D. M. Soluble molecules are key in maintaining the immunomodulatory activity of murine mesenchymal stromal cells. J. Cell. Sci. 125(Pt 1):200-208; 2012.

70. Liu, H.; McTaggart, S. J.; Johnson, D. W.; Gobe, G. C. Original article anti-oxidant pathways are stimulated by mesenchymal stromal cells in renal repair after ischemic injury. Cytotherapy. 14(2):162-172; 2012.

71. Liu, Z. Y.; Ganju, R. K.; Wang, J. F.; Schweitzer, K.; Weksler, B.; Avraham, S.; Groopman, J. E. Characterization of signal transduction pathways in human bone marrow endothelial cells. Blood. 90(6):2253-2259; 1997.

72. Lobo, M.; Zachary, I. Nuclear localization and apoptotic regulation of an amino-terminal domain focal adhesion kinase fragment in endothelial cells. Biochem. Biophys. Res. Commun. 276(3):1068-1074; 2000.

73. Lull, M. E.; Block, M. L. Microglial activation and chronic neurodegeneration. Neurotherapeutics. 7(4):354$365 ; 2010$.

74. Luo, Y.; Wang, Y.; Poynter, J. A.; Manukyan, M. C.; Herrmann, J. L.; Abarbanell, A. M.; Weil, B. R.; Meldrum, D. R. Pretreating mesenchymal stem cells with interleukin-1beta and transforming growth factor-beta synergistically increases vascular endothelial growth factor production and improves mesenchymal stem cell-mediated myocardial protection after acute ischemia. Surgery. 151(3):353-363; 2012.

75. Markel, T. A.; Wang, Y.; Herrmann, J. L.; Crisostomo, P. R.; Wang, M.; Novotny, N. M.; Herring, C. M.; Tan, J.; Lahm, T.; Meldrum, D. R. VEGF is critical for stem cell-mediated cardioprotection and a crucial paracrine factor for defining the age threshold in adult and neonatal stem cell function. American journal of physiology. Am. J. Physiol. Heart Circ. Physiol. 295(6):H2308-2314; 2008. 
76. Meisel, R.; Zibert, A.; Laryea, M.; Gobel, U.; Daubener, W.; Dilloo, D. Human bone marrow stromal cells inhibit allogeneic T-cell responses by indoleamine 2,3-dioxygenase-mediated tryptophan degradation. Blood. 103(12):4619-4621; 2004.

77. Minguell, J. J.; Erices, A. Mesenchymal stem cells and the treatment of cardiac disease. Exp. Biol. Med. (Maywood). 231(1):39-49; 2006.

78. Mirotsou, M.; Jayawardena, T. M.; Schmeckpeper, J.; Gnecchi, M.; Dzau, V. J. Paracrine mechanisms of stem cell reparative and regenerative actions in the heart. J. Mol. Cell. Cardiol. 50(2):280-289; 2011.

79. Mirotsou, M.; Zhang, Z.; Deb, A.; Zhang, L.; Gnecchi, M.; Noiseux, N.; Mu, H.; Pachori, A.; Dzau, V. Secreted frizzled related protein 2 (Sfrp2) is the key Akt-mesenchymal stem cell-released paracrine factor mediating myocardial survival and repair. Proc. Natl. Acad. Sci. U.S.A. 104(5):1643-1648; 2007.

80. Muller-Ehmsen, J.; Krausgrill, B.; Burst, V.; Schenk, K.; Neisen, U. C.; Fries, J. W.; Fleischmann, B. K.; Hescheler, J.; Schwinger, R. H. Effective engraftment but poor mid-term persistence of mononuclear and mesenchymal bone marrow cells in acute and chronic rat myocardial infarction. J. Mol. Cell. Cardiol. 41(5):876-884; 2006.

81. Murry, C. E.; Soonpaa, M. H.; Reinecke, H.; Nakajima, H.; Nakajima, H. O.; Rubart, M.; Pasumarthi, K. B.; Virag, J. I.; Bartelmez, S. H.; Poppa, V.; Bradford, G.; Dowell, J. D.; Williams, D. A.; Field, L. J. Haematopoietic stem cells do not transdifferentiate into cardiac myocytes in myocardial infarcts. Nature. 428(6983):664-668; 2004.

82. Nagaya, N.; Fujii, T.; Iwase, T.; Ohgushi, H.; Itoh, T.; Uematsu, M.; Yamagishi, M.; Mori, H.; Kangawa, K.; Kitamura, S. Intravenous administration of mesenchymal stem cells improves cardiac function in rats with acute myocardial infarction through angiogenesis and myogenesis. Am. J. Physiol. Heart Circ. Physiol. 287(6):H2670-2676; 2004.

83. Nasef, A.; Mathieu, N.; Chapel, A.; Frick, J.; Francois, S.; Mazurier, C.; Boutarfa, A.; Bouchet, S.; Gorin, N. C.; Thierry, D.; Fouillard, L. Immunosuppressive effects of mesenchymal stem cells: involvement of HLA-G. Transplantation. 84(2):231-237; 2007.

84. Ohkouchi, S.; Block, G. J.; Katsha, A. M.; Kanehira, M.; Ebina, M.; Kikuchi, T.; Saijo, Y.; Nukiwa, T.; Prockop, D. J. Mesenchymal stromal cells protect cancer cells from ROS-induced apoptosis and enhance the Warburg effect by secreting STC1. Mol. Ther. 20(2):417-423; 2012.

85. Okazaki, T.; Magaki, T.; Takeda, M.; Kajiwara, Y.; Hanaya, R.; Sugiyama, K.; Arita, K.; Nishimura, M.; Kato, Y.; Kurisu, K. Intravenous administration of bone marrow stromal cells increases survivin and Bcl-2 protein expression and improves sensorimotor function following ischemia in rats. Neurosci. Lett. 430(2):109-114; 2008.

86. Oltvai, Z. N.; Milliman, C. L.; Korsmeyer, S. J. Bcl-2 heterodimerizes in vivo with a conserved homolog, Bax, that accelerates programmed cell death. Cell. 74(4):609-619; 1993.

87. O'Reilly, M. S.; Holmgren, L.; Shing, Y.; Chen, C.; Rosenthal, R. A.; Moses, M.; Lane, W. S.; Cao, Y.; Sage, E. H.; Folkman, J. Angiostatin: a novel angiogenesis inhibitor that mediates the suppression of metastases by a Lewis lung carcinoma. Cell. 79(2):315-328; 1994.

88. Orlic, D.; Kajstura, J.; Chimenti, S.; Bodine, D. M.; Leri, A.; Anversa, P. Bone marrow stem cells regenerate infarcted myocardium. Pediatr. Transplant. 7 Suppl 3:86-88; 2003. 
89. Orlic, D.; Kajstura, J.; Chimenti, S.; Jakoniuk, I.; Anderson, S. M.; Li, B.; Pickel, J.; McKay, R.; Nadal-Ginard, B.; Bodine, D. M.; Leri, A.; Anversa, P. Bone marrow cells regenerate infarcted myocardium. Nature. 410(6829):701-705; 2001.

90. Orr, W. C.; Sohal, R. S. Extension of life-span by overexpression of superoxide dismutase and catalase in Drosophila melanogaster. Science. 263(5150):1128-1130; 1994.

91. Otsuru, S.; Tamai, K.; Yamazaki, T.; Yoshikawa, H.; Kaneda, Y. Circulating bone marrow-derived osteoblast progenitor cells are recruited to the bone-forming site by the CXCR4/stromal cell-derived factor-1 pathway. Stem Cells. 26(1):223-234; 2008.

92. Pan, G. Z.; Yang, Y.; Zhang, J.; Liu, W.; Wang, G. Y.; Zhang, Y. C.; Yang, Q.; Zhai, F. X.; Tai, Y.; Liu, J. R.; Zhang, Q.; Chen, G. H. Bone marrow mesenchymal stem cells ameliorate hepatic ischemia/reperfusion injuries via inactivation of the MEK/ERK signaling pathway in rats. J. Surg. Res. 178(2):935-948; 2012.

93. Pasha, Z.; Wang, Y.; Sheikh, R.; Zhang, D.; Zhao, T.; Ashraf, M. Preconditioning enhances cell survival and differentiation of stem cells during transplantation in infarcted myocardium. Cardiovasc. Res. 77(1):134$142 ; 2008$.

94. Penna, C.; Raimondo, S.; Ronchi, G.; Rastaldo, R.; Mancardi, D.; Cappello, S.; Losano, G.; Geuna, S.; Pagliaro, P. Early homing of adult mesenchymal stem cells in normal and infarcted isolated beating hearts. J. Cell. Mol. Med. 12(2):507-521; 2008.

95. Pittenger, M. F.; Martin, B. J. Mesenchymal stem cells and their potential as cardiac therapeutics. Circ. Res. 95(1):9-20; 2004.

96. Plotnikov, E. Y.; Khryapenkova, T. G.; Vasileva, A. K.; Marey, M. V.; Galkina, S. I.; Isaev, N. K.; Sheval, E. V.; Polyakov, V. Y.; Sukhikh, G. T.; Zorov, D. B. Cell-to-cell cross-talk between mesenchymal stem cells and cardiomyocytes in co-culture. J. Cell. Mol. Med. 12(5A):1622-1631; 2008.

97. Polchert, D.; Sobinsky, J.; Douglas, G.; Kidd, M.; Moadsiri, A.; Reina, E.; Genrich, K.; Mehrotra, S.; Setty, S.; Smith, B.; Bartholomew, A. IFN-gamma activation of mesenchymal stem cells for treatment and prevention of graft versus host disease. Eur. J. Immunol. 38(6):1745-1755; 2008.

98. Pons, J.; Huang, Y.; Arakawa-Hoyt, J.; Washko, D.; Takagawa, J.; Ye, J.; Grossman, W.; Su, H. VEGF improves survival of mesenchymal stem cells in infarcted hearts. Biochem. Biophys. Res. Commun. 376(2):419-422; 2008.

99. Pugh, C. W.; O'Rourke, J. F.; Nagao, M.; Gleadle, J. M.; Ratcliffe, P. J. Activation of hypoxia-inducible factor1; definition of regulatory domains within the alpha subunit. J. Biol. Chem. 272(17):11205-11214; 1997.

100. Ratajczak, J.; Wysoczynski, M.; Hayek, F.; Janowska-Wieczorek, A.; Ratajczak, M. Z. Membrane-derived microvesicles: important and underappreciated mediators of cell-to-cell communication. Leukemia. 20(9):1487-1495; 2006.

101. Ren, G.; Zhang, L.; Zhao, X.; Xu, G.; Zhang, Y.; Roberts, A. I.; Zhao, R. C.; Shi, Y. Mesenchymal stem cellmediated immunosuppression occurs via concerted action of chemokines and nitric oxide. Cell Stem Cell. 2(2):141-150; 2008.

102. Ripa, R. S.; Jorgensen, E.; Wang, Y.; Thune, J. J.; Nilsson, J. C.; Sondergaard, L.; Johnsen, H. E.; Kober, L.; Grande, P.; Kastrup, J. Stem cell mobilization induced by subcutaneous granulocyte-colony stimulating factor to improve cardiac regeneration after acute ST-elevation myocardial infarction: result of the 
double-blind, randomized, placebo-controlled stem cells in myocardial infarction (STEMMI) trial. Circulation. 113(16):1983-1992; 2006.

103. Rosova, I.; Dao, M.; Capoccia, B.; Link, D.; Nolta, J. A. Hypoxic preconditioning results in increased motility and improved therapeutic potential of human mesenchymal stem cells. Stem cells. 26(8):2173-2182; 2008.

104. Sattler, C.; Steinsdoerfer, M.; Offers, M.; Fischer, E.; Schierl, R.; Heseler, K.; Daubener, W.; Seissler, J. Inhibition of T-cell proliferation by murine multipotent mesenchymal stromal cells is mediated by CD39 expression and adenosine generation. Cell Transplant. 20(8):1221-1230; 2011.

105. Schuleri, K. H.; Boyle, A. J.; Hare, J. M. Mesenchymal stem cells for cardiac regenerative therapy. Handb. Exp. Pharmacol. (180):195-218; 2007.

106. Selmani, Z.; Naji, A.; Zidi, I.; Favier, B.; Gaiffe, E.; Obert, L.; Borg, C.; Saas, P.; Tiberghien, P.; Rouas-Freiss, N.; Carosella, E. D.; Deschaseaux, F. Human leukocyte antigen-G5 secretion by human mesenchymal stem cells is required to suppress $T$ lymphocyte and natural killer function and to induce CD4+CD25highFOXP3+ regulatory T cells. Stem cells. 26(1):212-222; 2008.

107. Shabbir, A.; Zisa, D.; Suzuki, G.; Lee, T. Heart failure therapy mediated by the trophic activities of bone marrow mesenchymal stem cells: a noninvasive therapeutic regimen. Am. J. Physiol. Heart Circ. Physiol. 296(6):H1888-1897; 2009.

108. Sheng, H.; Wang, Y.; Jin, Y.; Zhang, Q.; Zhang, Y.; Wang, L.; Shen, B.; Yin, S.; Liu, W.; Cui, L.; Li, N. A critical role of IFNgamma in priming MSC-mediated suppression of T cell proliferation through up-regulation of B7-H1. Cell Res. 18(8):846-857; 2008.

109. Shintani, S.; Murohara, T.; Ikeda, H.; Ueno, T.; Sasaki, K.; Duan, J.; Imaizumi, T. Augmentation of postnatal neovascularization with autologous bone marrow transplantation. Circulation. 103(6):897-903; 2001.

110. Sohal, R. S.; Ku, H. H.; Agarwal, S.; Forster, M. J.; Lal, H. Oxidative damage, mitochondrial oxidant generation and antioxidant defenses during aging and in response to food restriction in the mouse. Mech. Ageing Dev. 74(1-2):121-133; 1994.

111. Song, Y. S.; Lee, H. J.; Doo, S. H.; Lee, S. J.; Lim, I.; Chang, K. T.; Kim, S. U. Mesenchymal stem cells overexpressing hepatocyte growth factor (HGF) inhibit collagen deposit and improve bladder function in rat model of bladder outlet obstruction. Cell Transplant. 21(8):1641-1650; 2012.

112. Sudres, M.; Norol, F.; Trenado, A.; Gregoire, S.; Charlotte, F.; Levacher, B.; Lataillade, J. J.; Bourin, P.; Holy, X.; Vernant, J. P.; Klatzmann, D.; Cohen, J. L. Bone marrow mesenchymal stem cells suppress lymphocyte proliferation in vitro but fail to prevent graft-versus-host disease in mice. J. Immunol. 176(12):7761-7767; 2006.

113. Sun, Y. Q.; Deng, M. X.; He, J.; Zeng, Q. X.; Wen, W.; Wong, D. S.; Tse, H. F.; Xu, G.; Lian, Q.; Shi, J.; Fu, Q. L. Human Pluripotent Stem Cell-Derived Mesenchymal Stem Cells Prevent Allergic Airway Inflammation in Mice. Stem Cells. 30(12):2692-2699; 2012.

114. Tang, J.; Wang, J.; Yang, J.; Kong, X.; Zheng, F.; Guo, L.; Zhang, L.; Huang, Y. Mesenchymal stem cells overexpressing SDF-1 promote angiogenesis and improve heart function in experimental myocardial infarction in rats. Eur. J. Cardiothorac. Surg. 36(4):644-650; 2009. 
115. Tang, J. M.; Wang, J. N.; Zhang, L.; Zheng, F.; Yang, J. Y.; Kong, X.; Guo, L. Y.; Chen, L.; Huang, Y. Z.; Wan, Y.; Chen, S. Y. VEGF/SDF-1 promotes cardiac stem cell mobilization and myocardial repair in the infarcted heart. Cardiovasc. Res. 91(3):402-411; 2011.

116. Tang, Y. L.; Zhao, Q.; Qin, X.; Shen, L.; Cheng, L.; Ge, J.; Phillips, M. I. Paracrine action enhances the effects of autologous mesenchymal stem cell transplantation on vascular regeneration in rat model of myocardial infarction. Ann. Thorac. Surg. 80(1):229-236; 2005.

117. Tasso, R.; Ilengo, C.; Quarto, R.; Cancedda, R.; Caspi, R. R.; Pennesi, G. Mesenchymal stem cells induce functionally active T-regulatory lymphocytes in a paracrine fashion and ameliorate experimental autoimmune uveitis. Invest. Ophthalmol. Vis. Sci. 53(2):786-793; 2012.

118. Timmers, L.; Lim, S. K.; Arslan, F.; Armstrong, J. S.; Hoefer, I. E.; Doevendans, P. A.; Piek, J. J.; El Oakley, R. M.; Choo, A.; Lee, C. N.; Pasterkamp, G.; de Kleijn, D. P. Reduction of myocardial infarct size by human mesenchymal stem cell conditioned medium. Stem Cell Res. 1(2):129-137; 2007.

119. Tse, H. F.; Kwong, Y. L.; Chan, J. K. F.; Lo, G.; Ho, C. L.; Lau, C. P. Angiogenesis in ischaemic myocardium by intramyocardial autologous bone marrow mononuclear cell implantation. Lancet. 361(9351):47-49; 2003.

120. Urbanek, K.; Rota, M.; Cascapera, S.; Bearzi, C.; Nascimbene, A.; De Angelis, A.; Hosoda, T.; Chimenti, S.; Baker, M.; Limana, F.; Nurzynska, D.; Torella, D.; Rotatori, F.; Rastaldo, R.; Musso, E.; Quaini, F.; Leri, A.; Kajstura, J.; Anversa, P. Cardiac stem cells possess growth factor-receptor systems that after activation regenerate the infarcted myocardium, improving ventricular function and long-term survival. Circ. Res. 97(7):663-673; 2005.

121. Valgimigli, M.; Rigolin, G. M.; Cittanti, C.; Malagutti, P.; Curello, S.; Percoco, G.; Bugli, A. M.; Della Porta, M.; Bragotti, L. Z.; Ansani, L.; Mauro, E.; Lanfranchi, A.; Giganti, M.; Feggi, L.; Castoldi, G.; Ferrari, R. Use of granulocyte-colony stimulating factor during acute myocardial infarction to enhance bone marrow stem cell mobilization in humans: clinical and angiographic safety profile. Eur. Heart J. 26(18):1838-1845; 2005.

122. Wang, G. L.; Jiang, B. H.; Rue, E. A.; Semenza, G. L. Hypoxia-inducible factor 1 is a basic-helix-loop-helixPAS heterodimer regulated by cellular O2 tension. Proc. Natl. Acad. Sci. U.S.A. 92(12):5510-5514; 1995.

123. Wang, S. P.; Wang, Z. H.; Peng, D. Y.; Li, S. M.; Wang, H.; Wang, X. H. Therapeutic effect of mesenchymal stem cells in rats with intracerebral hemorrhage: reduced apoptosis and enhanced neuroprotection. Mol. Med. Report. 6(4):848-854; 2012.

124. Ward, P. A. The sepsis seesaw: seeking a heart salve. Nat. Med. 15(5):497-498; 2009.

125. Whone, A. L.; Kemp, K.; Sun, M.; Wilkins, A.; Scolding, N. J. Human bone marrow mesenchymal stem cells protect catecholaminergic and serotonergic neuronal perikarya and transporter function from oxidative stress by the secretion of glial-derived neurotrophic factor. Brain Res. 1431:86-96; 2012.

126. Wiehe, J. M.; Kaya, Z.; Homann, J. M.; Wohrle, J.; Vogt, K.; Nguyen, T.; Rottbauer, W.; Torzewski, J.; Fekete, N.; Rojewski, M.; Schrezenmeier, H.; Moepps, B.; Zimmermann, O. GMP-adapted overexpression of CXCR4 in human mesenchymal stem cells for cardiac repair. Int. J. Cardiol. 2012.

127. Xiang, J.; Tang, J.; Song, C.; Yang, Z.; Hirst, D. G.; Zheng, Q. J.; Li, G. Mesenchymal stem cells as a gene therapy carrier for treatment of fibrosarcoma. Cytotherapy. 11(5):516-526; 2009. 
Copyright (C) 2013 Cognizant Communication Corporation

128. Yagi, H.; Soto-Gutierrez, A.; Parekkadan, B.; Kitagawa, Y.; Tompkins, R. G.; Kobayashi, N.; Yarmush, M. L. Mesenchymal stem cells: Mechanisms of immunomodulation and homing. Cell Transplant. 19(6):667-679; 2010.

129. Yamagiwa, S.; Gray, J. D.; Hashimoto, S.; Horwitz, D. A role for TGF-beta in the generation and expansion of CD4+CD25+ regulatory T cells from human peripheral blood. J. Immunol. 166(12):7282-7289; 2001.

130. Yang, S. H.; Park, M. J.; Yoon, I. H.; Kim, S. Y.; Hong, S. H.; Shin, J. Y.; Nam, H. Y.; Kim, Y. H.; Kim, B.; Park, C. G. Soluble mediators from mesenchymal stem cells suppress T cell proliferation by inducing IL-10. Exp. Mol. Med. 41(5):315-324; 2009.

131. Yousef, M.; Schannwell, C. M.; Kostering, M.; Zeus, T.; Brehm, M.; Strauer, B. E. The BALANCE Study: clinical benefit and long-term outcome after intracoronary autologous bone marrow cell transplantation in patients with acute myocardial infarction. J. Am. Coll. Cardiol. 53(24):2262-2269; 2009.

132. Yu, J.; Li, M.; Qu, Z.; Yan, D.; Li, D.; Ruan, Q. SDF-1/CXCR4-mediated migration of transplanted bone marrow stromal cells toward areas of heart myocardial infarction through activation of PI3K/Akt. J. Cardiovasc. Pharmacol. 55(5):496-505; 2010.

133. Zarjou, A.; Kim, J.; Traylor, A. M.; Sanders, P. W.; Balla, J.; Agarwal, A.; Curtis, L. M. Paracrine effects of mesenchymal stem cells in cisplatin-induced renal injury require heme oxygenase-1. American journal of physiology. Renal Physiol. 300(1):F254-262; 2011.

134. Zhang, S.; Jia, Z.; Ge, J.; Gong, L.; Ma, Y.; Li, T.; Guo, J.; Chen, P.; Hu, Q.; Zhang, P.; Liu, Y.; Li, Z.; Ma, K.; Li, L.; Zhou, C. Purified human bone marrow multipotent mesenchymal stem cells regenerate infarcted myocardium in experimental rats. Cell Transplant. 14(10):787-798; 2005.

135. Zhang, Z.; Li, H.; Ma, Z.; Feng, J.; Gao, P.; Dong, H.; Zhang, Z. Efficient cardiomyogenic differentiation of bone marrow mesenchymal stromal cells by combination of Wnt11 and bone morphogenetic protein 2 . Exp. Biol. Med. 237(7):768-776; 2012. 


\section{Figure legend}

\section{Figure 1. Action modes of MSCs.}

1) Trans-differentiation: Mesenchymal Stem Cells (MSCs) possess the ability to differentiate into another cell type, including ectoderm, mesoderm and endoderm; 2) Cell-fusion: MSC fuses with another cell to form a multinuclear cell known as syncytium; 3) Mitochondrial transfer: MSC makes contact with the adjacent cell, and a gap junctional channel (GJC) is built. MSC transfers its mitochondria to the impaired cell through this GJC; 4) Microvesicles: MSC releases microvesicles containing RNA, mRNA or/and protein to the microenvironment. The cell nearby engulfs these microvesicles through endocytosis process; 5) Paracrine: MSC secrets bioactive cytokines and chemokines that act on immunomodulation, angiogenesis/arteriogenesis, antiapoptosis, anti-oxidation and cell migration/stimulation. 
Copyright (C 2013 Cognizant Communication Corporation

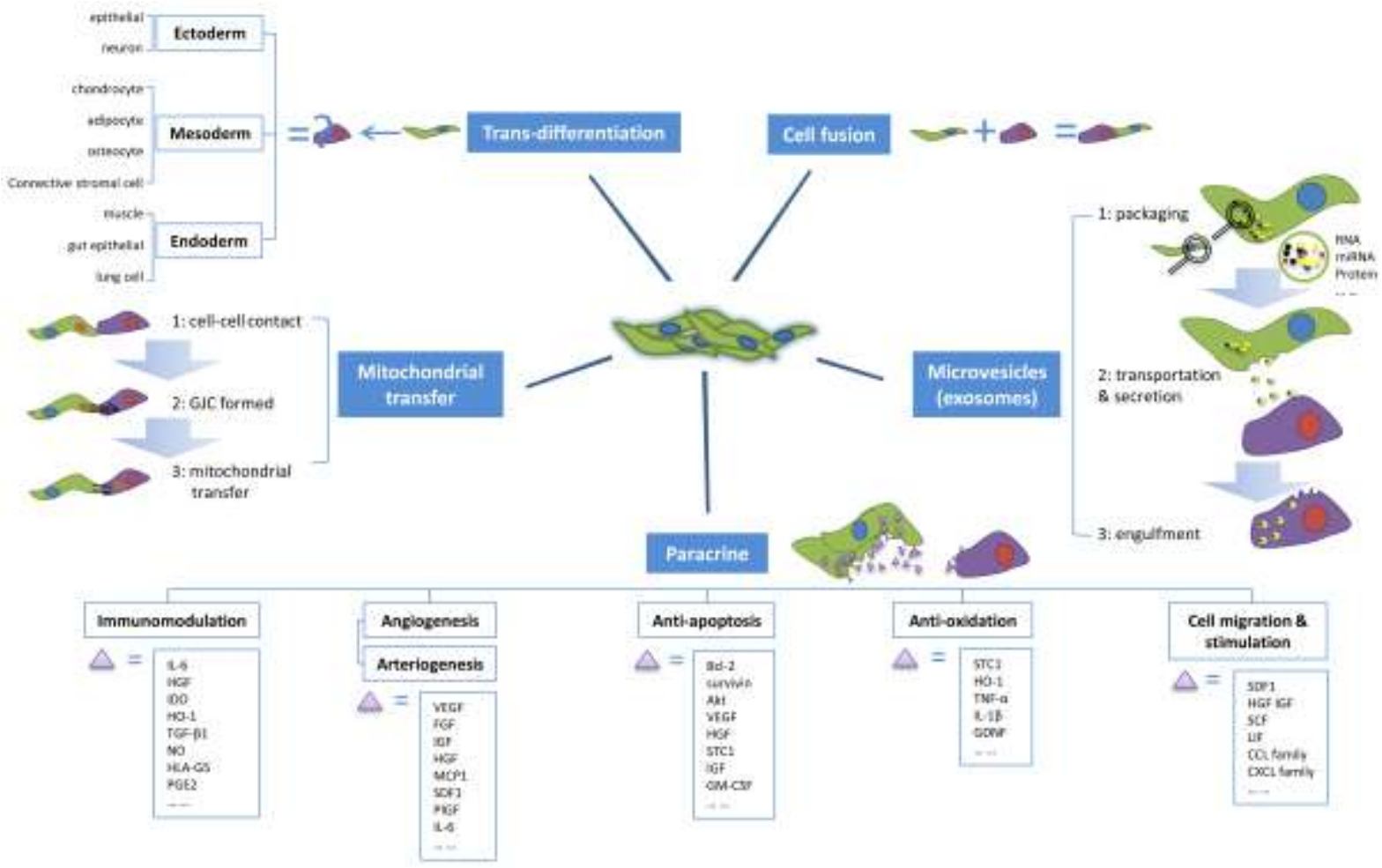

Figure 1 